\title{
Psychiatric and medical co-morbidities among the substance abusers at a tertiary hospital in north Bihar- A clinical study
}

\author{
Anirban Chakrabarti ${ }^{1}$, Nivedita Choudhury ${ }^{2 *}$ \\ ${ }^{1}$ Associate Professor. \{Department of Psychiatry\}, ${ }^{2}$ Associate Professor. \{Department of Ophthalmology\}, Mata Gujri Memorial Medical \\ College and Lions Sevakendra Hospital, Kishanganj, Bihar. INDIA. \\ Email: chakrabarti.a@gmail.com
}

\begin{abstract}
Background: Substance abuse with traditional Indian drugs is a common practice in social gatherings all over India. Cannabis, opium, methaqualone, barbiturates and minor tranquilizers are the most often abused drugs. Heroin abuse was first reported in 1985 and since then it became a common drug abused among the youths and psychiatric patients. Intravenous drug use (IDU) became a matter of concern in the recent years with the increased spread of HIV-AIDS. The present study is an attempt to study the substance abuse pattern in a tertiary hospital in north Bihar and to find out the comorbid psychiatric and medical illnesses in the patients attending the Psychiatry OPD. Materials and Methods: It was a cross-sectional study done for a period of one year on 209 substance abusers in a tertiary hospital of north Bihar. The sample was analyzed separately with respect to age and sex. The pattern of substance abuse and the psychiatric and medical co-morbidities associated with it were analyzed with respect to age and sex. Results and Observations: The study found that $89 \%$ of substance abusers were males. Among the males, $48 \%$ were abusing alcohol and $47 \%$ were abusing polysubstance. $27 \%$ were intravenous drug abusers and $17 \%$ showed high risk behavior. Among the females, $55 \%$ of the female patients were abusing alcohol. The percentage of women abusing poly-substance was $32 \%$ and polysubstance and alcohol was $14 \%$. The number of female patients involved in high-risk behavior was only $4(18 \%)$. Intravenous drug abuse and high-risk behavior was commoner in age group less than 25 years than in the age group of more than 25 years. 19\% received a psychiatric co-morbid diagnosis and 39.7\% received a medical co-morbid diagnosis. Discussion: Substance abuse is commoner in men (89\%) than women $(11 \%)$ in north Bihar. The results are inconformity with the previous studies that found male preponderance of substance abuse 5 . Alcohol was the commonest substance of abuse $(55 \%)$ and the proportion of intravenous drug abusers were $27 \%$ which was higher than the national figure of $19 \% .5$ The study also showed that $91 \%$ of substance abusers $<25$ years of age abused polysubstance and $47 \%$ of them were intravenous drug abusers which reflected the changing pattern of substance abuse among the youths. The present study also showed psychiatric co-morbidities in 19\% which shows that substance abuse is common in psychiatric patients. Conclusion: The high proportion of young people abusing intravenous drugs in north Bihar reflects the high people to people contact with the neighboring north-eastern states and Nepal. The situation is alarming and demands urgent intervention.
\end{abstract}

Key Words: substance abuse, psychiatric co-morbidities, medical co-morbidities.

*Address for Correspondence:

Dr. Nivedita Choudhury, M.S, Associate Professor. Department of Ophthalmology, Mata Gujri Memorial Medical College and Lions Sevakendra Hospital, Kishanganj, Bihar, INDIA.

Email: chakrabarti.a@gmail.com

Received Date: 20/11/2019 Revised Date: 18/12/2019 Accepted Date: 07/01/2020 DOI: https://doi.org/10.26611/1071311

\begin{tabular}{|l|l|}
\hline \multicolumn{2}{|c|}{ Access this article online } \\
\hline Quick Response Code: & Website: \\
\hline & www.medpulse.in \\
\cline { 2 - 2 } & \\
\hline
\end{tabular}

\begin{abstract}
INTRODUCTION
Alcohol, opium and cannabis have been the traditional drugs of use in India with moderate consumption being ritualized in social gatherings (Ganguly et.al. 1995) ${ }^{1}$. Studies published in mid 1970s and 1980s showed that cannabis, opium, methaqualone, barbiturates and minor tranquilizers were most often abused substances (Channabasavanna 1998, Siddiqui and Britto 1997). ${ }^{2}, 7$ Heroin abuse was first reported in 1985 (Mohan et.al 1985). ${ }^{3}$ Since then drug abuse has become common in school and college students, non-student youths and
\end{abstract}

How to cite this article: Anirban Chakrabarti, Nivedita Choudhury. Psychiatric and medical co-morbidities among the substance abusers at a tertiary hospital in north Bihar- A clinical study. MedPulse - International Journal of Psychology. January 2020; 13(1): 01-04. $\underline{\text { http://www.medpulse.in }}$ 
psychiatric patients (Sharma 1995) ${ }^{4}$.A study conducted in 9 urban centers across India on drug abusers found that $43 \%$ were abusing alcohol, $51 \%$ different opioids and $6 \%$ cannabis (Mittal and Ch'ien 1998). The study farther found that the mean age of the subjects was 33 yrs., $98 \%$ male, $57 \%$ were married and about $26 \%$ were unemployed. It also revealed that $19 \%$ of all drug abusers were IDUs and highest incidence of IDU was reported from Manipur (80\%). A study conducted in 5 different centers in India (Dorabjee and Sampson, 2000) ${ }^{6}$ showed that more than $50 \%$ of the subjects from a particular center have had sex with multiple partners. It also showed that sharing of needles amongst IDUs were between 52\%$81 \%$. The present study is conducted to evaluate the substance abuse pattern and the associated medical and psychiatric co-morbidities among the out patients of a tertiary hospital in north Bihar.

\section{AIMS AND OBJECTIVES}

1. To study the substance abuse pattern in a tertiary hospital in North Bihar.

2. To document the co-morbid psychiatric and medical illnesses amongst the patients attending the Psychiatry OPD.

\section{MATERIAL AND METHODS}

Table 1: Age distribution of the sample $(n=209)$

\begin{tabular}{|c|c|c|c|c|c|}
\hline & & MALE & FEMALE & & \\
\hline & AGE & & & & \\
\hline & MEAN & 32.417 & 33.91 & & \\
\hline & SD & 10.351 & 12.463 & & \\
\hline & MAXIMUM & 70 & 55 & & \\
\hline & MINIMUM & 16 & 15 & & \\
\hline & MEDIAN & 31 & 33.5 & & \\
\hline & & MALE & FEMALE & & \\
\hline & & & & $\mathrm{X}^{2}$ & $\mathrm{P}$ \\
\hline SUBSTANCE & ABUSE & & & 3.287 & 0.193 \\
\hline $\mathrm{ALCHOH}$ & & 90 & 12 & & \\
\hline ALCHOHOL AND P & LSUBSTANCE & 10 & 3 & & \\
\hline POLSUBST & ANCE & 87 & 7 & & \\
\hline IDU & & 50 & 1 & 0.372 & 0.542 \\
\hline HRB & & 32 & 4 & & \\
\hline
\end{tabular}

Table 2: Pattern of substance abuse with respect to sex:

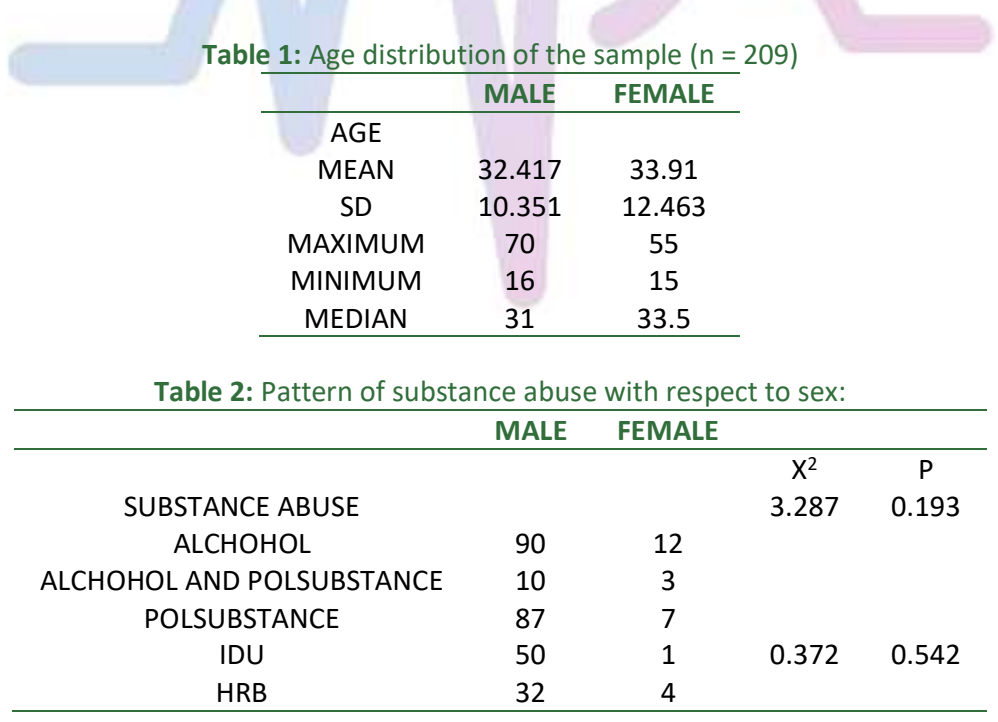

\section{RESULTS AND OBSERVATIONS}

The sample size of the present study was 209 consisting of 187 males and 22 females. The total sample was analyzed separately with respect to age and sex. There were 53 patients below 25 years and 156 patients $\geq 25$ years. The mean age of male patients was 32.41 years (16-70 years) with $\mathrm{SD} \pm 10.35$ years. On the other hand, the mean age of female patients was 33.91 years $(15-55$ years) with $\mathrm{SD} \pm 12.46$ years. 
Table 3A: Psychiatric co-morbidities with respect to sex:

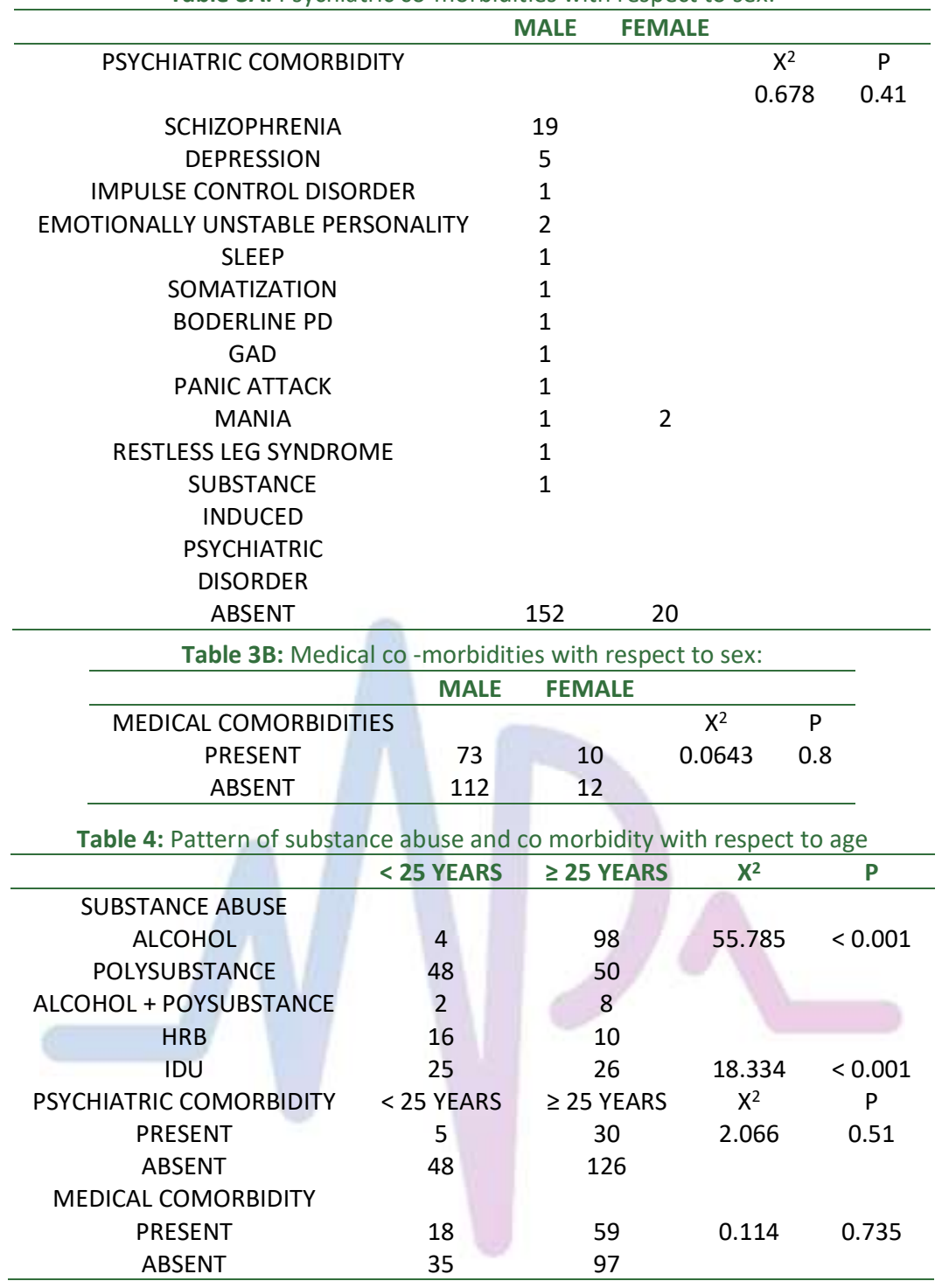

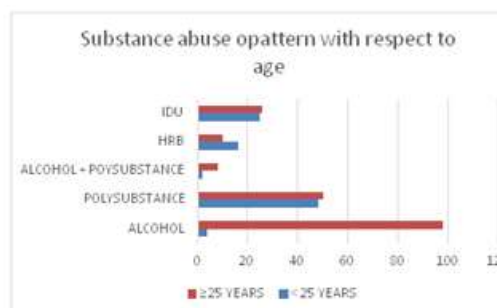

Substance abuse pattern with respect to sex: Among the male patients $48 \%(\mathrm{n}=90)$ were abusing alcohol and $47 \%(n=87)$ were abusing poly-substance. The number of patients abusing both polysubstance and alcohol was 10 $(5 \%) .57 \%(n=50)$ of poly-substance abusers were doing so by intravenous route. Of all the males $27 \%(n=50)$ were IDUs. $17 \%(n=32)$ of the male patients reported high risk behavior (sharing needles, unprotected sex, and multiple sex partners). On the other hand, $55 \%(n=12)$ of the female patients were abusing alcohol. The percentage of women abusing poly-substance and poly-substance and alcohol was $32 \%(n=7)$ and $14 \%(n=3)$ respectively. The number of female patients involved in high risk behavior was only $4(18 \%)$.

Co-morbidity with respect to sex: $19 \%(n=35)$ of all male patients received a psychiatric co-morbid diagnosis. 
Of all the male patients with psychiatric co-morbidity $54 \%(n=19)$ were suffering from schizophrenia and $14 \%$ $(\mathrm{n}=5)$ had depression. On the other hand, only 2 female patients $(9 \%)$ had psychiatric co-morbidity. Both these patients were diagnosed to be suffering from bipolar affective disorder. $40 \%$ of all male patients $(\mathrm{n}=75)$ had a medical co-morbidity and the figures for the female patients were $45 \%(n=10)$.

Substance abuse pattern with respect to age: The sample size was divided into two groups, one $<25$ years and the other $\geq 25$ years. There were 53 patients $(25 \%)<$ 25 years and 156 patients $(75 \%) \geq 25$ yrs. $91 \%$ of the patients $(\mathrm{n}=48)<25$ years were abusing poly-substance while only $6 \%(\mathrm{n}=3)$ were abusing alcohol $(\mathrm{P}<0.05)$. $47 \%$ $(\mathrm{n}=25)$ of the $<25$ years patients had a history of IDU and $30 \% \quad(\mathrm{n}=16)$ reported having high risk behavior. In contrast $63 \%(\mathrm{n}=98)$ of the patients $\geq 25$ years were abusing alcohol and $32 \%(\mathrm{n}=50)$ had a history of polysubstance abuse. Only $17 \%$ of this group $(n=26)$ had a history of IDU $(\mathrm{P}<0.001)$ and only $6 \%(\mathrm{n}=10)$ reported high risk behavior. Co-morbidity pattern with respect to age: $19 \%(n=30)$ of the patients $\geq 25$ years had received a diagnosis of psychiatric co-morbidity, while only $9 \%$ $(n=5)$ of patients $<25$ years received the same. The rate of medical co-morbidity was similar in both the groups. The figures were $38 \%(\mathrm{n}=59)$ for people $\geq 25$ years and $34 \%(\mathrm{n}=18)$ for people $<25$ years.

\section{DISCUSSION}

The present study shows $89 \%$ of the patients were male and $55 \%$ of all patients were abusing alcohol. These figures are in conformity with the previous finding of alcohol as the most widely abused substance and male preponderance of substance abuse (Mittal and Ch'ien $1998)^{5}$. However, the number of females in this study was $11 \%$, which is higher than the earlier studies. This can be explained by the fact that women drinking alcohol is accepted by the society here and it is a part of rituals in tribals. The mean age of patients in the present study is 33 years which is exactly the same with the findings of Mittal and Ch'ien's 1998 study. ${ }^{5} 27 \%$ of the abusers in the present study were IDUs. This figure is higher than the national figure of $19 \%$ but lower than the rates of Manipur $(80 \%)$. The higher than the national figures could be explained by the proximity of North Bihar to Nepal and the north-eastern states. Dorabjee and Sampson $(2000)^{6}$ in their study found that $52 \%-81 \%$ of the substance abusers were sharing needles. But the present study found high risk behavior (which includes needle sharing) in only $17 \%$ of the subjects. This probably indicates increased awareness amongst patients about routes of HIV transmission and the effectiveness of the syringe exchange program run by NGOs and supported by state government. Sharma in 1995 found that substance abuse is common in people with a psychiatric diagnosis. This has been reflected in the present study which found that $19 \%$ of all male patients received a psychiatric diagnosis. The figure for females in this study was only $9 \%$. This was possibly because of low sample size. The present study shows that $91 \%$ of patients $<25$ years were abusing poly-substance and almost half of these $(47 \%)$ were IDUs. This shows emergence of changing pattern in substance abuse and a greater number of younger people at risk.

\section{CONCLUSION}

North Bihar is geographically close to some of the northeastern states and Nepal with high prevalence of IDUs and high-risk behavior. Large number of people in this region migrate outside Bihar to different parts of India and Nepal for earning and livelihood giving rise to increased people to people contact. In this context, higher than national figure of IDU and number of young people abusing poly-substance is alarming.

Limitations: This study did not include all the patients of the tertiary hospital. Only those patients who came for consultation voluntarily entered in this study.

Abbreviations: HRB- high risk behavior. IDUintravenous drug users. GAD-generalized anxiety disorder. PD- personality disorder.

\section{REFERENCES}

1. Ganguly K K, Sharma H K and Krishnamachari K A V R (1995). "An ethnographic account of opium consumers of Rajasthan." Addiction. 90, 9-12.

2. Channabasavanna S M (1989). "Epidemiology of Drug Abuse in India - An Overview.” In R Ray and R W Pickens (Eds.). Proceedings of Indo-US symposium on Alcohol and Drug Abuse. NIMHANS Publication No. 20, 43-55.

3. Mohan D, Adityanjee, Saxena S and Lal S (1985). "Changing Trend in Heroin Abuse in India." Bulletin on Narcotics, 37, 19-24.

4. Sharma H K (1995). "Drug Abuse Consequences and Responses, India Country Report." Report submitted to the Ministry of Health and Family Welfare, Government of India.

5. Mittal S and Ch'ien J M N (1998). "Developing Community Drug Rehabilitation. Rapid Assessment Study of Drug Abuse in Target Communities in India." Report submitted to Ministry of Social Justice and Empowerment, Government of India, International Labour Organisation and United Nations International Drug Control Programme, Regional Office for South Asia.

6. Dorabjee J and Samson L (2000). "A multi-centre rapid assessment of injecting drug abuse in India." International Journal of Drug Policy. 11, 99-112.

7. Siddiqui H Y and Britto G K (1997). "Drug Abuse in Mumbai City." Report submitted to Ministry of Social Justice and Empowerment, Government of India.

\section{Source of Support: None Declared} Conflict of Interest: None Declared 